of the same patient. Ann Rheum Dis 1994; 53: 823-7.

8 Roos H, Dahlberg L, Lohmander L S. Proteoglycan fragments in joint fluid after exercise. Scand $\mathcal{F}$ Med Sci Sports 1993; 3: 127-30.

9 Roos H, Dahlberg L, Hoerrner L A, et al. Markers of cartilage matrix metabolism in joint fluid and serum after exercise. Osteoarthritis Cartilage 1995; 3: 7-14.

10 Saxne T. Matrix molecules as markers for cartilage involvement in inflammatory joint disease versity, 1987.

11 Bensen C V, Dahners L R, Lester G E, Caterson $B$. Evidence for degenerative changes in Son B. Evidence for degenerative changes in
articular cartilage of the contralateral 'control' knees in the Pond-Nuki model of osteoknees in the Pond-Nuki model of osteo-
arthrosis. Trans Orthop Res Soc 1995; 20: 97.

\section{Autosomal dominant undifferentiated spondyloarthropathy not related to the HLA system}

We were interested to read the article by Kidd and colleagues ${ }^{1}$ on familial aggregation for undifferentiated spondyloarthropathy associated with HLA-B7. The authors described a single family in whom numerous members had a recurrent seronegative arthropathy or enthesopathy, or both, which fulfilled the European Spondylarthropathy Study Group criteria for spondyloarthropathy ${ }^{2}$ in the absence of the HLA-B27 tissue type, coexistent psoriasis, or inflammatory bowel disease. They suggested that 'undifferentiated' spondyloarthropathy can be associated with genetic factors other than HLA-B27. We are in total agreement.

A few years ago, we studied a French family of 83 members distributed over five generations divided into four main branches, among whom 18 adult members had destructive arthropathy and enthesopathic changes. ${ }^{34}$ In all patients, the disease began between the ages of 18 and 32 years. It affected predominantly the wrists, fingers, shoulders, and peripheral entheses and progressed as an oligoarthritis, with intermittent inflammatory episodes lasting for one to three months. Axial involvement of the cervical and lumbar spine and the sacroiliac joints was also seen, but was not prominent. The sites of involvement seemed to be influenced by mechanical factors. The right wrist was generally the first joint to be

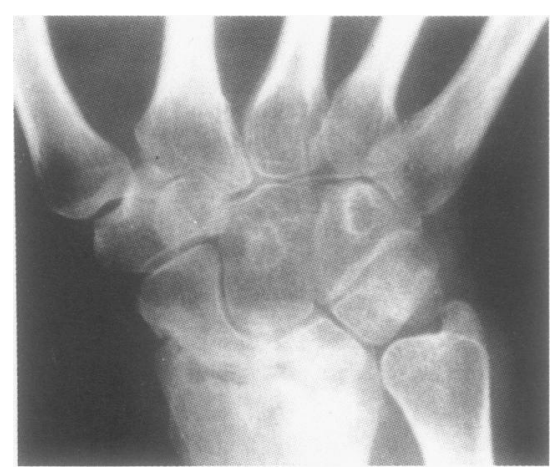

Radiograph of the right wrist of a 29 year old female patient (disease duration six years), showing destruction of the radiocarpal joint. affected. Destructive abnormalities, followed by bony proliferation, and intra- or extraarticular bony ankylosis were the main radiological features of this familial arthropathy (figure).

The transmission of the disease was dominant and autosomal, with $100 \%$ penetrance. The clinical and radiological features were strikingly similar in all patients in successive generations and different branches of the genealogical tree, suggesting monogenic transmission. HLA typing of 12 patients and 13 healthy family members was performed. No HLA antigen was linked to the disease. None of the affected subjects had antigens B27, DR4 or DR7. The disease was not transmitted with any particular HLA haplotype.

Tests for rheumatoid factor yielded negative results. There was no history of psoriasis or chronic enteropathy in the members of this family. In none of the 18 patients did the arthropathy fulfil the American Rheumatism Association criteria. ${ }^{5}$ A diagnosis of ankylosing spondylitis was also eliminated, because the New York criteria were not fulfilled. ${ }^{6}$ This familial arthropathy could belong to the class of undifferentiated spondyloarthropathies proposed by Burns and Calin. ${ }^{7}$ The spondyloarthropathies have in common a non-specific inflammation of the entheses, involving both the chondrified and the calcified parts. After a destructive phase, which causes bony erosion, repair takes the form of ossification. ${ }^{89}$ An inherited abnormality in the collagen matrix of the enthese may predispose to destructive arthropathy and enthesopathic changes. Linkage analysis excluded COL $2 \mathrm{Al}$ as the disease causing locus in this family. ${ }^{10}$ Further studies are needed to identify the genetic locus responsible for the disease.

A GAUCHER P PERE P GILLE'

Department of Rheumatology, URA CNRS 1288 CHU de Nancy Brabois, Rue du Morvan, 54511 Vandoeuvre lès Nancy, France

Correspondence to: A Gaucher.

1 Kidd B L, Wilson P J, Evans P R, Cawley $M$ I D. Familial aggregation of undifferentiated spondyloarthropathy associated with HLA-B7. Ann Rheum Dis 1995; 54: 125-7.

2 Dougados $M$, van der Linden S, Juhlin $R$, et a The European Spondylarthropathy Study Group preliminary criteria for the classifica Group preliminary criteria for the classifica1991; 34: 1218-30.

3 Gaucher A, Weryha G, Dang-Vu V, Moreau P, Péré P. Autosomal dominant spondyloPére P. Autosomal dominant spondylo-
arthropathy. N Engl f Med 1989; 320: 940-1.

4 Gaucher A, Weryha G, Perrier P, et al. Autosomal dominant arthropathy in a French family. Arthritis Rheum 1991; 34: 738-43.

5 Arnett F C, Edworthy S M, Bloch D A, et al The American Rheumatism Association 1987 revised criteria for the classification of rheumatoid arthritis. Arthritis Rheum 1988, 31: 315-24.

6 Bennett P H, Burch T A. Population studies of the rheumatic diseases. Amsterdam: Excerpta Medica, 1968

7 Burns T A, Calin A. Undifferentiated spondylarthropathies. In: Calin A, ed. Spondylarthrop athies. Orlando: Grune and Stratton, 1984, 253-64.

8 Ball J. Enthesopathy of rheumatoid and ankylosing spondylitis. Ann Rheum Dis 1971; 30: 213-23.

9 Gaucher A, Péré P, Régent D, Grandhaye P, Aussedat R, Vivard T. Spondylarthropathies Aussedat $R$, Vivard $T$. Spondylarthropathies
ou polyenthésites ossifiantes: arguments scinou polyenthésites ossifiantes: arguments scintigraphiques et scanographiques.
Mal Osteoartic 1987; 54: 243-8.

10 Superti-Furga A, Steinmann B, Lee B, et al. Autosomal dominant spondylarthropathy: $\mathrm{n}$ linkage to the type II collagen gene. $N$ Eng f Med 1990; 322: 552-3.

\section{LETTERS TO THE EDITOR}

\section{HLA associations of systemic lupus erythematosus in Chinese from Singapore}

A role for genetic factors in systemic lupus erythematosus (SLE) is strongly suggested by the substantial excess recurrence of the disease in monozygotic compared with dizygotic twins. ${ }^{1}$ Genes within the major histocompatibility complex (MHC) contribute to SLE, but it has proved difficult to establish the precise locus(i) involved. Studying populations from diverse ethnic backgrounds can help to identify these loci for two reasons: first, there are substantial differences in gene frequencies (for example HLA) between different races; second, different MHC haplotypic combinations of alleles in different races can help to identify the primary relationships with disease, rather than those secondary to linkage disequilibrium. Previous studies in white populations have shown associations with HLA-DR3 and -DR2; ${ }^{3}$ however, studies from south east Asia, while revealing a strong association with DR2 in Koreans ${ }^{4}$ and Chinese from Hong Kong 5 and Malaysia, did not reveal the association with DR3 observed in white subjects.

We studied HLA-DRB1 and -DQB1 alleles in 26 Chinese SLE patients (25 female) attending the National University Hospital in Singapore, and in 77 Chinese controls from the same area. All patients met four or more American Rheumatism Association criteria for SLE. The mean age was 36 years (range 20-64), and mean disease duration $7 \cdot 1$ years (range 1-20) Patients with any known non-Chinese ethnicity (Indians, Malayans, Europeans) were excluded. Renal involvement was present in $57 \%$ of the patients, arthritis in $46 \%$, malar rash in $36 \%$, central nervous system involvement in $21 \%$, photosensitivity in $7 \cdot 1 \%$, and discoid lupus in $3 \cdot 6 \%$. Antinuclear antibodies were present in $96 \%$ of patients and $92 \%$ had dsDNA antibodies.

HLA-DRB1 alleles were assigned by polymerase chain reaction (PCR) amplification of genomic DNA probed with sequence specific oligonucleotides. ${ }^{7}$ HLADQB1 alleles were typed by PCR using sequence specific primer pairs. ${ }^{8}$ The statistical significance of differences between the groups was analysed using the $\chi^{2}$ test.

The table shows the DR and DQ frequencies. There were non-significant increases in DR3, DR8, and DR9, but not in DR2. Furthermore, DQ2 and $D^{\star} 0601$ were increased in the patients, but this was almost certainly due to linkage with DR3 and DR8, respectively. None of the DR or DQ antigens was associated with particular clinical manifestations of SLE.

Our data are interesting with respect to other published results from Asian populations. HLA-DR9, for instance, was found to be increased in Chinese SLE patients from Hong Kong ${ }^{5}$ and Korea, in whom there was 
$H L A-D R$ and $D Q$ antigen frequencies observed in SLE patients and controls from Singapore

\begin{tabular}{|c|c|c|c|c|}
\hline \multirow[t]{2}{*}{ Antigen } & \multicolumn{2}{|c|}{$\begin{array}{l}S L E \\
(n=26)\end{array}$} & \multicolumn{2}{|c|}{$\begin{array}{l}\text { Controls } \\
(n=77)\end{array}$} \\
\hline & $n$ & $\%$ & $n$ & $\%$ \\
\hline DR1 & 0 & & 0 & \\
\hline DR2 & 7 & $26 \cdot 9$ & 21 & $27 \cdot 3$ \\
\hline DR3 & 7 & $26 \cdot 9$ & 12 & $15 \cdot 6$ \\
\hline DR4 & 7 & $26 \cdot 9$ & 17 & $22 \cdot 1$ \\
\hline DR7 & 0 & & 7 & $9 \cdot 1$ \\
\hline DR8 & 7 & $26 \cdot 9$ & 13 & $16 \cdot 9$ \\
\hline DR9 & 9 & $34 \cdot 6$ & 19 & $24 \cdot 7$ \\
\hline DR10 & 1 & 3.8 & 4 & $5 \cdot 2$ \\
\hline DR11 & 2 & $7 \cdot 7$ & 12 & $15 \cdot 6$ \\
\hline DR12 & 5 & $19 \cdot 2$ & 20 & $26 \cdot 0$ \\
\hline DR13 & 1 & $3 \cdot \overline{8}$ & 3 & 3.9 \\
\hline DR14 & 1 & 3.8 & 9 & $11 \cdot 7$ \\
\hline DQ2 & 6 & $23 \cdot 6$ & 13 & $16 \cdot 9$ \\
\hline DQ4 & 4 & $15 \cdot 3$ & 9 & 11.7 \\
\hline DQ5 & 7 & $26 \cdot 9$ & 18 & $23 \cdot 4$ \\
\hline DQ6 & 15 & $57 \cdot 7$ & 33 & $42 \cdot 8$ \\
\hline DQ0601 & 10 & $38 \cdot 4$ & 23 & 29.9 \\
\hline $\mathrm{DQ}^{\star} 0602$ & 3 & $10 \cdot 7$ & 7 & $9 \cdot 1$ \\
\hline $\mathrm{DQ}^{\star} 0603-8$ & 2 & $7 \cdot 6$ & 3 & 3.9 \\
\hline DQ7 & 7 & $26 \cdot 9$ & 31 & $40 \cdot 3$ \\
\hline DQ8 & 5 & $19 \cdot 2$ & 8 & $10 \cdot 4$ \\
\hline DQ9 & 8 & $30 \cdot 7$ & 25 & $32 \cdot 5$ \\
\hline
\end{tabular}

$\star \chi^{2}=0.99$; odds ratio $2.0 ; 95 \%$ confidence interval 0.51 to $7.83 ; p=0.09$.

also a non-significant increase in DR8. ${ }^{4}$ However, our most striking finding was the absence of a DR2 association with SLE, as this had been found in the studies from Hong Kong and Korea ${ }^{4}$ and in a further study from Kuala Lumpur, Malaysia. ${ }^{6}$

One possible explanation for these differences could be genetic admixture in the Singapore Chinese population, as there has been some intermarriage with Malays, Indians, and Europeans since the seventeenth century. In contrast, Hong Kong Chinese rarely marry non-Chinese. This could explain the presence in the Singapore SLE patients of the typical white population SLE susceptibility haplotype carrying DR3 and DQ2. Another explanation could be ethnic heterogeneity among the southern Chinese. In Singapore, for example, approximately $75 \%$ of the Chinese migrated from Furjian Province, whereas $90 \%$ or more of the Hong Kong Chinese came from Guangdong Province. Unfortunately, the HLA distributions in these populations are not well characterised, but there may be significant differences which could have implications for the relative frequencies of MHC haplotypes (particularly DR2) predisposing to SLE in these populations.

MARTIN RUDWALEIT KATHRYN GIBSON PAUL WORDSWORTH Nuffield Department of Clinical Medicine, fohn Radcliffe Hospital, Oxford, United Kingdom Queen Elizabeth Hospital, Woodville, Adelaide 5011, Australia
VERNON OH

National University Hospital, Singapore 0511

Correspondence to: Dr P Wordsworth, Nuffield Department of Clinical Medicine, John Radcliffe Hospital, Oxford OX3 9DU, United Kingdom.

$M$ Rudwaleit is supported by the Deutschen Akademischen Austauschdienst (DAAD). The authors are grateful for the financial support of the Arthritis and Rheumatism Council.

1 Deapen D, Escalante A, Weirib L, et al. A revised estimate of twin concordance in systemic lupus erythematosus. Arthritis Rheum 1992; 35: 311-7.

2 Hartung K, Baur M P, Coldeway R, et al. Major histocompatibility complex haplotypes and complement $\mathrm{C} 4$ alleles in systemic lupus erythematosus. 7 Clin Invest 1992; 90: 1346-51.

3 Davies E J, Hillerby M C, Cooper R G, et al. HLA-DQ, DR and complement C4 variants in systemic lupus erythematosus. $\mathrm{Br} \mathcal{F}$ Rheumatol 1993; 32: 870-5.

4 Hong G H, Kim H Y, Takeuchi F, et al. Association of complement C4 and HLA-DR alleles with systemic lupus erythematosus in Koreans. $\mathcal{f}$ Rheumatol 1994; 21 : 442-7.

5 Hawkins B R, Lam Wong K, Wong R W S, Ho Chan $K$, Dunckley $H$, Serjeantson $S W$ Chan K, Dunckley $H$, Serjeantson $S$. Strong association between the major histoerythematosus in southern Chinese. $f$ Rheumatol 1987; 14: $1128-31$.

6 Doherty D G, Ireland R, Demaine A G, et al. Major histocompatibility complex genes and susceptibility to systemic lupus erythematosus in southern Chinese. Arthritis Rheum 1992; 35: 641-6.

7 Wordsworth B W, Allsopp C E M, Young R P, Bell J I. HLA-DR typing using DNA amplification by the polymerase chain reaction and sequential hybridization to sequence-specific oligonucleotide probes. Immunogenetics 1990; 32: 413-8.

8 Bunce M, Taylor C J, Welsh K I. Rapid HLADQB typing by eight PCR amplifications with sequence-specific primers (PCR-SSO). Hum Immunol 1993; 37: 201-6.

\section{Treatment of refractory reflex sympathetic dystrophy with pamidronate}

Reflex sympathetic dystrophy (RSD) is a condition affecting part or the whole of a limb, and is characterised by pain, vasomotor disturbance and trophic changes. RSD can persist for months or years and be severely disabling. ${ }^{1}$ On radiographs, it is characterised by local osteoporosis, which corresponds to osteoclast hyperactivity. Calcitonin, an antiosteoclastic drug, has been shown to help some patients. ${ }^{2}$ Pamidronate, a second generation biphosphonate, is a potent antiosteoclastic agent, ${ }^{3}$ which is the rationale for using it in the treatment of RSD.

In an open prospective study, we evaluated the efficacy of pamidronate in the treatment of refractory RSD. Eleven patients (three men and eight women; mean age 51.3 (SD 12.8) years) suffering from RSD of at least six months duration (mean of 14.6 $(10 \cdot 3)$ months), refractory to calcitonin and physical therapy, were included. All patients fulfilled Doury's criteria for the diagnosis of RSD. ${ }^{4}$ The involved sites were the foot $(n=5)$, the hand $(n=2)$, the upper limb $(n=2)$, the knee $(n=1)$, the lower limb $(n=1)$. In eight cases, the RSD was related to local injury. Six patients had had to stop work because of RSD.

Radiographs of the affected sites showed osteopenia in all cases. The patients were given $30 \mathrm{mg}$ of intravenous pamidronate in $500 \mathrm{ml}$ of saline over four hours, daily, for three consecutive days. The patients received no standard treatment for their RSD from one month before the administration of pamidronate until three months after it. Patients were assessed by the same observer at baseline and after one and three months. Evaluation consisted of a visual analogue scale for pain (VAS), and a physician global assessment (no improvement, moderate, significant or excellent improvement) based on objective signs on clinical evaluation (hyperhydrosis, vasomotor changes, joint stiffness). Blood cell count and serum calcaemia (corrected with serum albuminaemia) were measured before, during, and one and three days after the administration of pamidronate.

The mean VAS decreased from $58 \cdot 8 / 100$ $(20 \cdot 2)$ before therapy, to $41 \cdot 1 / 100(26 \cdot 8)$ at one month $(\mathrm{p}<0.05$; Wilcoxon paired test) and $33 \cdot 8 / 100(29)$ at three months $(p<0.01)$. In the physician global assessment, the results were: no improvement $(n=4)$, moderate improvement $(n=1)$, significant improvement $(n=3)$, and excellent improvement $(n=3)$ at one and three months. Three of the six patients who had had to stop work had returned to work after three months. We were unable to find predictive factors for efficacy (age, gender, affected site, degree of osteopenia). Pamidronate was well tolerated, apart from classical minor adverse effects: two patients had a transient fever, two patients had brief, asymptomatic hypocalcaemia $(2.05 \mathrm{mmol} / \mathrm{l})$ and one patient had hypocalcaemia $(2 \mathrm{mmol} / \mathrm{l})$ associated with perioral paraesthesia which resolved rapidly with oral calcium treatment ( $1 \mathrm{~g} /$ day).

It is not possible to say whether the observed improvements were attributable to the treatment, the natural history of the disease, or psychological factors, as pamidronate was not compared with placebo in a double blind trial. However, more than $50 \%$ of the patients suffering from chronic disease, previously refractory to treatment, showed significant or excellent improvement while taking pamidronate, suggesting that it was effective.

In conclusion, this study suggests that pamidronate is a safe and effective drug for the treatment of some refractory cases of RSD. Further double blind trials are required to confirm these results.

JEAN FRANCIS MAILLEFERT
CHRISTINE CHATARD
SUSANNAH OWEN
THIERRY PEERE
CHRISTIAN TAVERNIER
Department of Rheumatology,
Hopital Général, Dijon, France

JACQUES TEBIB

Department of Rheumatology,

Pierre Benite, France

Correspondence to: $\mathrm{Dr} J \mathrm{~F}$ Maillefert, Service de
Rhumatologie, Hôpital Général, 3 rue du Fb Rhumes, 21000 Dijon, France.

1 Chard M D. Diagnosis and management of algodystrophy. Ann Rheum Dis 1991; 50: $727-30$

2 Gobelet C, Meier J L, Schaffner W, BischoffDeloye A, Gerster J C, Burckhardt P. Calcitonin and reflex sympathetic dystrophy syndrome. Clin Rheumatol 1986; 5: 382-8.

3 Fitton A, McTavish D. Pamidronate. Drugs 1991; 41: 289-318.

4 Doury P, Dirheimer Y, Pattin S. Algodystrophy. Berlin, Heidelberg, New York: Springer, 1981.

\section{Pericardial tamponade preceding cutaneous involvement in systemic sclerosis}

Cardiac involvement in systemic sclerosis may be primary, or secondary to involvement of other organ systems. Primary cardiac involvement in systemic sclerosis may be manifested as pericardial disease, myocardial disease, conduction system abnormalities, or cardiac arrhythmias. ${ }^{1}$ Cardiac symptoms do not usually appear until late in the disease, but exceptionally may precede the recog- 